\title{
Bone Pathology: Osteopoikilosis
}

\author{
Tolga Tolunay ${ }^{1}$, Arslan Kaan Arslan ${ }^{1}$, Izzet Bingol ${ }^{2 *}$, Vedat Bicici ${ }^{2}$, Mehmet Eren ${ }^{1}$, \\ Cheikh Moustapha Mohamed Lemine ${ }^{3}$, Kasim Kilicarslan ${ }^{2}$
}

${ }^{1}$ Department of Orthopaedics and Traumatology, Yenimahalle Public Hospital, Ankara, Turkey; ${ }^{2}$ Department of Orthopaedics and Traumatology, Ankara Ataturk Training and Research Hospital, Yildirim Beyazit University, Ankara, Turkey; ${ }^{3}$ Department of Orthopaedics and Traumatology, Centre Hospitalier National, Nouakchott, Mauritania.

Email: tolgatolunay@hotmail.com, arslankagan@gmail.com,*dr.izzetbingol@hotmail.com,dr_vedatbicici@yahoo.com, drmehmeteren@hotmail.com, cerebih@yahoo.fr, kilicarslan44@hotmail.com

Received July $15^{\text {th }}, 2013$; revised August $14^{\text {th }}, 2013$; accepted August $31^{\text {st }}, 2013$

Copyright (C) 2013 Tolga Tolunay et al. This is an open access article distributed under the Creative Commons Attribution License, which permits unrestricted use, distribution, and reproduction in any medium, provided the original work is properly cited.

\begin{abstract}
Osteopoikilosis is a rare benign sclerotic bone dysplasia. The disease which usually develops asymptomatically is coincidentally diagnosed with direct radiographs. Our subject, a 52-year-old male was admitted to our policlinic two days ago due to turning of his left ankle causing pain and swelling on his left ankle. We asked for bilateral direct radiograph of left ankle. The left ankle radiograph indicates multiple, small oval/round hyperdense sclerotic regions. As a result of available clinical finding and radiological viewing, the patient was diagnosed with osteopoikilosis.
\end{abstract}

Keywords: Osteopoikilosis; Bone Pathology; Hyperdense Sclerotic Regions

\section{Introduction}

Osteopoikilosis is a rare benign sclerotic bone dysplasia. Autosomal dominant inheritance is observed, and the cause of the pathology is unknown [1]. The disease which usually develops asymptomatically is coincidentally diagnosed with direct radiographs [2]. In this case presentation, we discuss a subject who was admitted to our policlinic due to turning of his left ankle causing pain and swelling on the left ankle, and who was then diagnosed with osteopoikilosis by means of direct radiographs.

\section{Case Presentation}

The patient, a 52-year-old male was admitted to our policlinic two days ago due to turning of his left ankle causing pain and swelling on his left ankle. His family had no history suggestive of osteopoikilozis. He had a history of hyperthyroidism and thyroid medication use. Orthopaedic examination indicated that he had swell, oedema and tenderness on left ankle medial malleolus level. Anterior tensile test was negative and the medial malleolus level did not have any gap. Inversion stress test (Varus stress test) and Peroneal tendon instability test were negative. Bilateral direct radiograph was asked for the patient. The

"Corresponding author. left ankle radiograph did not show any finding which corresponds to fracture but the bone structures contained multiple, small oval-round hyperdense sclerotic regions. In order to find out the distribution of lesions, we asked for radiographs of bilateral ankle, bilateral knee, bilateral hand-wrist, anteroposterior pelvis, bilateral lumbosacral, posteroanterior lung which includes bilateral shoulder joints and bilateral skull. We have discovered that specified lesions are symmetrically distributed around bilateral hand-wrist (Figure 1(a)), bilateral foot-ankle (Figure 1(b)), bilateral knee joint (Figure 1(c)), bilateral shoulder joint (Figure 1(d)) and bilateral hip joint (Figure 1(e)). Ankle magnetic resonance (Figures 2(a)-(b)) examination carried out on the external centre indicated that lesions having similar features were monitored on bone structures. The patient did not have active complaints about locations which correspond to lesions as indicated in direct radiographs. Complete blood count, alkene phosphatase, serum calcium, phosphor and magnesium levels, parathyroid hormone, erythrocyte sedimentation rate, $\mathrm{C}$ reactive protein, liver and kidney function tests and D vitamin levels were normal. Bone mineral densitometry measures of the patient were within normal levels. TSH level of the patient was high and free T4 level was low, and the patient was referred to endocrine department for consultation. As a result of the consultation, the patient was recommended thyroid hormone 


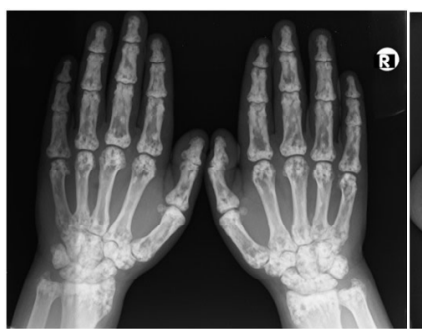

(a)

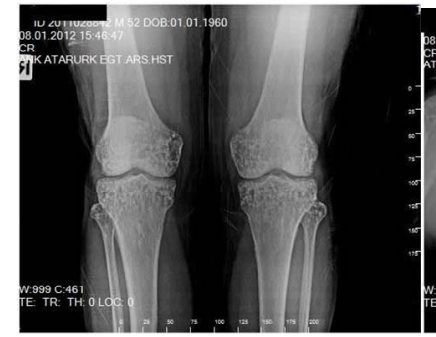

(c)

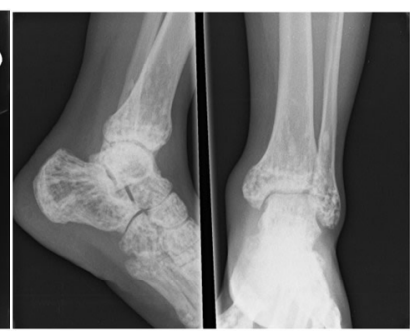

(b)

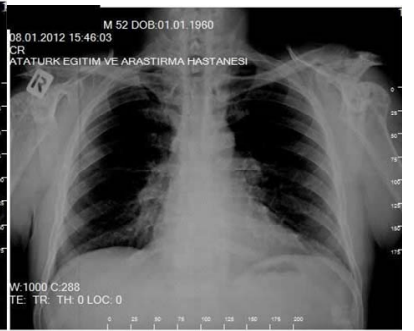

(d)

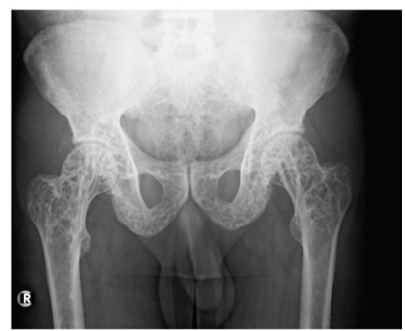

(e)

Figure 1. (a) Bilateral hand-wrist; (b) Foot-ankle; (c) Bilateral knee joint; (d) Bilateral shoulder joint; (e) Bilateral hip joint.

treatment by the endocrine department. The department did not provide additional recommendations for bone pathology. We prescribed orthopaedic follow-up for the patient due to the current situation.

\section{Discussion}

Osteopoikilosis is a rare benign sclerotic bone dysplasia. Autosomal dominant inheritance is observed and the reason of the pathology is unknown [1]. The disease which usually develops asymptomatically is coincidentally diagnosed with direct radiographs [2]. The patients are generally asymptomatic, yet pain can be a rare symptom of the disease [3]. Characteristically, the disease is observed in direct radiographs as multiple oval and round densities have $2-10 \mathrm{~mm}$ size on epiphyseal and metaphyseal regions on long bones [4]. The studies indicate that the disease is inherited, and has autosomal dominant inheritance [4-6]. Patients with osteopoikilosis should be followed up with regard to complications such as malignant transformation, spinal stenosis and hip fracture although the course of disease is benign [2]. During differential diagnosis, osteoblastic metastases, tuberous sclerosis,

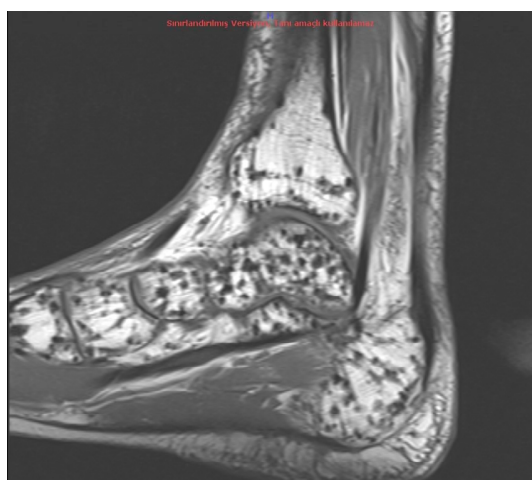

(a)

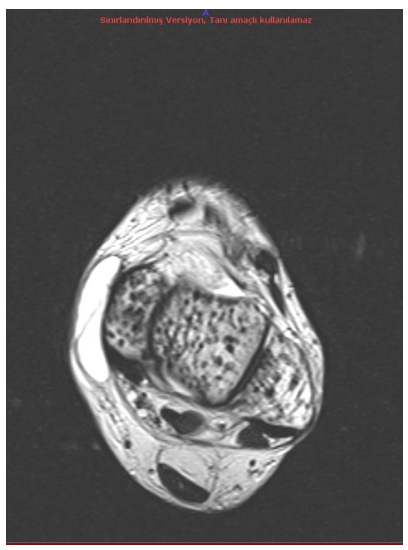

(b)

Figure 2. Ankle magnetic resonance.

mastocytosis, osteopathy, striata, melorheostosis must be taken into consideration. Osteopoikilosis can be distinguished by symmetrical distribution, metaphyseal and epiphyseal involvement and uniform size of the lesions [1]. Lesions descried on our subject were observed to be symmetrical with metaphyseal and epiphyseal involvement. In conclusion, patients with osteopoikilosis remain asymptomatic and diagnosed incidentally on direct radiographs take separates from other diseases. Patients with osteopoikilosis must be advised that the disease has benign course, and similar pathologies can be found with their family members, and they must be followed-up for possible complications.

\section{REFERENCES}

[1] S. Appenzeller, G. R. W. Castro and I. B. Coimbra, "Osteopoikilosis with Abnormal Bone Scan Long-Term Follow-Up," Journal of Clinical Rheumatology, Vol. 13, No. 5, 2007, pp. 291-292. doi:10.1097/RHU.0b013e318156d987

[2] M. F. Inci, U. E. Vurdem, H. Gümüş and R. Inci, "Case Report of a Patient with Osteopoikilosis," Rheumatology International, Vol. 32, No. 9, 2011, pp. 2829-2832.

[3] M. M. Aghdashi and M. Rabiepoor, "Osteopoikilosis: Pain as a Presenting Symptom in Three Family Mem- 
bers," Clinical Medicine Insights: Arthritis and Musculoskeletal Disorders, Vol. 4, 2011, pp. 29-32. doi:10.4137/CMAMD.S7035

[4] I. T. Benli, S. Akalin, E. Boysan, E. F. Mumcu, M. Ki and D. Türkolu, "Epidemiological, Clinical and Radiological Aspects of Osteopoikilosis," Journal of Bone \& Joint Surgery, Vol. 74, No. 4, 1992, pp. 504-506.

[5] S. Baasanjav, A. Jamsheer, M. Kolanczyk, D. Horn, K. Hoffmann, A. Latos-Bielenska, S. Mundlos and T. Latos, "Osteopoikilosis and Multiple Exostoses Caused by No- vel Mutations in LEMD3 and EXT1 Genes RespectivelyCoincidence within One Family, Baasanjav et al.," BMC Medical Genetics, Vol. 11, 2010, p. 110. doi:10.1186/1471-2350-11-110

[6] E. Ben-Asher, E. Zelzer and D. Lancet, "LEMD3: The Gene Responsible for Bone Density Disorders (Osteopoikilosis)," Israel Medical Association Journal, Vol. 7, No. 4, 2005, pp. 273-274. 